Exploring the relationship between multiple team membership and team performance: the role of social networks and collaborative technology

\author{
Fabiola Bertolotti $^{*}$ \\ Elisa Mattarelli \\ Matteo Vignoli \\ Diego Maria Macrì
}

\author{
Department of Sciences and Methods for Engineering \\ University of Modena and Reggio Emilia \\ Via Amendola 2, Padiglione Morselli \\ 42122 Reggio Emilia, Italy

$$
\begin{aligned}
& \text { Tel: +390522 } 522611 \\
& \text { Fax: +390522 } 522609
\end{aligned}
$$

Email: fabiola.bertolotti@unimore.it

${ }^{(*)}$ Corresponding author

Forthcoming in Research Policy 


\title{
Exploring the relationship between multiple team membership and team performance: the role of social networks and collaborative technology
}

\begin{abstract}
Firms devoted to research and development and innovative activities intensively use teams to carry out knowledge intensive work and increasingly ask their employees to be engaged in multiple teams (e.g. $R \& D$ project teams) simultaneously. The literature has extensively investigated the antecedents of single teams performance, but has largely overlooked the effects of multiple team membership (MTM), i.e., the participation of a focal team's members in multiple teams simultaneously, on the focal team outcomes. In this paper we examine the relationships between team performance, MTM, the use of collaborative technologies (instant messaging), and work-place social networks (external advice receiving). The data collected in the R\&D unit of an Italian company support the existence of an inverted U-shaped relationship between MTM and team performance such that teams whose members are engaged simultaneously in few or many teams experience lower performance. We found that receiving advice from external sources moderated this relationship. When MTM is low or high, external advice receiving has a positive effect, while at intermediate levels of MTM it has a negative effect. Finally, the average use of instant messaging in the team also moderated the relationship such that at low levels of MTM, R\&D teams whose members use instant messaging intensively attain higher performance while at high levels of MTM an intense use of instant messaging is associated with lower team performance. We conclude with a discussion of theoretical and practical implications for innovative firms engaged in multitasking work scenarios.
\end{abstract}

Keywords: Multiple Team Membership (MTM), R\&D team performance, social networks, external advice receiving, collaborative technologies, instant messaging 


\section{Exploring the relationship between multiple team membership and team performance: the role of social networks and collaborative technology}

\section{Introduction}

Organizations increasingly adopt work teams to perform knowledge intensive tasks and coordination activities (Hoegl and Proserpio, 2004; Ferriani et al., 2009; Zaccaro et al., 2012). Furthermore, to respond to fast-paced and dynamic environments, knowledge professionals in organizations, like software developers and R\&D employees, are frequently engaged in multiple project teams simultaneously. In other words, professionals often hold multiple team memberships, being concurrently members of several teams in a given period of time (O'Leary et al., 2011). According to O'Leary and colleagues (2012), more than 80\% of knowledge workers experience work situations of multiple team membership, especially in the field of new product development and software development, i.e. in organizations strongly involved with innovative work and R\&D.

As organizations' achievements depend more and more on the work of teams, the comprehension of the way they function and how to improve their performance is becoming increasingly important. While extant research has undoubtedly enriched our knowledge on the antecedents of single teams effectiveness (see Cohen and Bailey, 1997 and Mathieu et al., 2008 for comprehensive reviews of theorical models on teams), it has largely overlooked the role played by the fact that members of a single team, in practice, often hold memberships also in other teams generating, at the team level, a situation of multi-team membership (MTM) (although notable exceptions do exist; see, e.g., Cummings and Haas, 2012; O'Leary et al., 2011). Consequently, we know little about if and how the multiple commitments held by professionals working in a MTM context influence the processes and the performance of the single teams in which they are involved. Dynamics of multiple membership are likely to generate both positive and negative consequences on single teams. For instance, through multiple memberships, knowledge, best practices, and other resources can flow between R\&D teams; however, the way individual members allocate their time across the different teams can influence single teams processes and pose serious challenges to their functioning. Because of the increasing evidence of innovative organizations adopting this form of organizing (Chan, 2014), exploring the relationships between MTM and team performance is therefore of both theoretical and practical importance (O’Leary et al., 2011; Tennenbaum et al., 2012). Moreover, the very few studies that focused on the topic of MTM offer us a puzzling picture that calls for additional and more nuanced understanding of how the belongingness of individuals to multiple teams simultaneously creates challenges in attaining high levels of team performance. On one hand, O'Leary and colleagues (2011), in the first theoretical contribution that explicitly investigates the relationship between MTM and teams productivity, propose the existence of an inverted curvilinear relationship so that intermediate 
levels of MTM allow teams to gain higher productivity because they push team members to develop better team work practices and to pay more attention to the way they allocate their time. Conversely, in their empirical study of knowledge-intensive teams, Cummings and Haas (2012) found that multiple team membership was positively related to team performance; such result is consistent with Chan (2014) who studied engineering project teams.

We embrace and aim to extend this stream of literature. A first goal of the present empirical study is to further explore the relationship between MTM and team outcomes by focusing specifically on the performance of $R \& D$ teams. We thus help explaining the inconsistent evidence above described and, by paying attention to team performance, above and beyond team productivity, we focus on an outcome of paramount importance for R\&D contexts. As we will expand upon later, we first draw from attention based theories and knowledge acquisition theories (e.g. Hansen, 1999; Hansen and Haas, 2001; Ocasio 1997) to argue that teams characterized by extreme levels of MTM (very low and very high) attain lower performance than teams operating at intermediate levels of MTM.

Furthermore, our work extends theoretical models on teams and team performance by unraveling the interacting role of MTM with other factors. As a matter of fact, the investigation of the relationship between MTM and team performance is made more complex by the intervention of moderating factors. O'Leary and colleagues (2011) suggest that moderating factors can be at organizational (e.g., incentive systems), team (e.g., geographic dispersion), and individual level of analysis (e.g., time related individual preferences, individuals' networks of relationships). A second objective of this paper is to focus on moderators that originate at the individual level of analysis, i.e. external advice receiving and collaborative technology use. The explanation for focusing on these variables follows.

In a new work scenario where $R \& D$ professionals are engaged in different teams simultaneously, a situation that poses challenges for teams and their members (Wageman et al., 2012a), individuals and teams make use of their social and technological resources in order to better accomplish their tasks. This creates a complex set of interdependencies between new forms of teams, collaborative technologies, and members interactions that make the processes of organizing team work for successful performance more complex than previously theorized.

It is well known that modern workplaces are experiencing profound changes in how people interact (i.e. how they build social networks) and how they use collaborative technology (e.g., email and IM). For instance, Adecco reports that, as workers are more and more fragmented across projects and locations, the promotion of interactions between individuals who may rarely meet face to face, above and beyond the participation in shared projects, becomes fundamental. In addition, collaborative technology is now pervasive in the workplace and is expected to support and even improve collaboration in teams (Bertrand, 2014). However, social and technological resources are likely to generate both positive and negative consequences on single teams that are also dependent on the combination of individuals on multiple teams simultaneously. For instance, in terms of social resources, it is acknowledged that the presence in a team of internal networks where members are 
connected to each other and of external ties that connect team members to external resources may be beneficial in helping individuals and teams to accomplish their tasks and gain better performance (e.g. Ancona and Caldwell, 1992; Sparrowe et al., 2001). More specifically, receiving advice from external sources helps team members to acquire inputs that can be incorporated in team work practices. At the same time, external social networks require a valuable resource, like time, to be managed and maintained (Day and Kilduff, 2003) thereby increasing the coordination costs that teams have to face. We thus expect that the effect of MTM on team performance, via its effect on informational and attention resources, will be influenced by the level of external advice receiving available to team members.

In order to strive in MTM scenarios, professionals also make an intensive use of collaborative technologies (e.g., email, instant messaging, project management systems) to keep in touch with a large number of colleagues who could be co-located or dispersed. Among different collaborative technologies, in this paper we focus on instant messaging (IM), that has now become a common means of communication in work contexts (Tudor and Pettely, 2010; Radicati, 2012) and is suitable to $R \& D$ contexts because its quasi-synchronous features and likely "polychronic" use (e.g., Dennis et al., 2010). While on the one hand IM can help teams in accessing knowledge and information and managing individuals' availability (Garrett and Danziger, 2007), on the other hand it is a source of potential disruptive interruptions (Rennecker and Godwin, 2005). Once again, in a MTM scenario, it is not enough to consider how a team uses a technology like instant messaging because the configurations of individuals on multiple teams simultaneously likely interact, via their effects on coordination and attention, with the single teams' ability to use effectively the technology to increase their performance.

Therefore, the second aim of the paper is to investigate how external advice receiving networks and instant messaging use in teams moderate the relationship between MTM and team performance. In particular we posit that higher levels of external advice receiving and instant messaging use are associated to enhanced team performance but only for teams characterized by a low to intermediate levels of MTM.

We explore these issues through a field study conducted in the R\&D unit of a major Italian firm in the alternative energy industry. The present research intends to make several contributions. To our knowledge, it is one of the few studies to empirically assess the relationship between MTM and team outcomes, specifically team performance, in an $R \& D$ work setting. It therefore adds to the very recent stream of literature on new forms of work that started to acknowledge the changed and complex settings in which project-based organizations operate today (e.g., Ferriani et al., 2009) and to the theoretical models on teams and teamwork (e.g., Wageman et al., 2012b). In addition to that, we enrich our comprehension of new moderators (social networks and use of collaborative technologies) that may affect the relationship between MTM and R\&D team performance. As such, our study contributes to an enhanced understanding of the contingent value of relational and technological 
resources for professionals operating in a multi-team membership scenario. Accordingly, we offer new insights on how to better support organizations that adopt MTM as a way of structuring work and favoring innovation processes. Finally, our research has specific implications for R\&D managers who are responsible, at the same time, for allocating their coworkers' time along a variety of projects to attain efficiency as well as to maximize the innovative performance, and for helping coworkers to navigate in such work contexts.

\section{Hypotheses development}

The model in Figure 1 summarizes the hypotheses presented in the following paragraphs.

Insert Figure 1 about here

\subsection{MTM and team performance}

Because of the widespread use of teams, both localized and distributed, in knowledge-intensive organizations, scholars and practitioners have devoted considerable attention to explore the predictors of team performance in terms of both design factors, e.g. size, composition, diversity, and emerging social processes, e.g. conflict, trust, identification (for an extensive review see Mathieu et al., 2008). Team performance captures the idea that teams must produce outputs considered as adequate by those who receive or who are in charge of evaluating them (Wageman et al., 2005).

Surprisingly, previous research has mainly focused on single teams performance and has largely overlooked the role played by the fact that members of a single team are, in practice, often involved in multiple teams simultaneously (e.g., Chudoba and Watson-Manheim, 2007; Mathieu et al., 2008; Bercovitz and Feldman, 2011). Modern organizations, indeed, often ask their members to be involved, concurrently, in different projects and activities and, even in a single workday, professionals may find themselves working on a number of heterogeneous tasks and interacting with a number of different teammates. Multiple team membership, therefore, entails the necessity for professionals to switch between tasks but also between team contexts, as different project teams may be characterized by differing tasks as well as different members, locations, routines, and identities (O'Leary et al., 2011). Those dynamic environments can lead to both positive and negative effects on teams' internal states and processes calling for new models of team performance that take into account how the above factors drive performance.

O'Leary and colleagues (2011), in their seminal theoretical contribution that explicitly investigates, at the team level, the relationship between the number of teams people are simultaneously involved and the productivity of teams (expressed in terms of amount of time used to produce a given output and the utilization of people's active time on single projects) propose the existence of an inverted curvilinear relationship. At intermediate levels of MTM, teams gain higher 
productivity because their members are prompted to develop better team work practices and to pay more attention to the way they allocate their time. Very low MTM, on the contrary, does not force team members to engage in these virtuous processes because they are endowed with enough resources and time to complete their tasks and do not search for new ways of improving their efficiency. Very high levels of MTM tax too much team members' attention and cognitive resources, leading to reduced productivity.

Building on this research, we aim to investigate the link between MTM and single team performance. We argue that, based on theories of knowledge acquisition (Cummings, 2004; Hansen, 1999, Reagans and McEvily, 2003; Zellmer-Bruhn, 2003) and attention (Hansen and Haas, 2001; Leroy, 2009; Ocasio, 1997), at intermediate levels of MTM teams will attain higher performance as compared to teams whose members experience situations of extreme MTM (very low and very high). Being involved in more than one team can lead to potential positive consequences for each single team for a number of beneficial mechanisms. According to knowledge acquisition theories, working within different team contexts enriches professionals through the acquisition of different points of view, information and knowledge that can be transferred within the focal team (e.g. Cross and Cummings, 2004; Cummings, 2004; Reagans and McEvily, 2003). Empirical evidence finds that a single team quickly develops routines and recurrent ways of doing things that tend to persist over time and limit the level of experimentation of new ways of carrying out activities (Zellmer-Bruhn, 2003). If the application of routines helps a team to save time and to reduce the level of uncertainty, it can also reduce the likelihood of engaging in innovative thinking with the consequence of potentially limiting team performance especially in the case of knowledge intensive work and R\&D teams (Gersick and Hackman, 1990; Zellmer-Bruhn, 2003). Bringing new perspectives inside one team through the participation of members in other teams can therefore have an overall positive impact on a single team performance, provided that teams will be able to reconsider existing ways of doing things in light of the new information acquired and to apply new knowledge to the team activities. Consistent with this argument, Cummings and Haas (2012) and Chan (2014) found that multiple team membership was positively related to the performance of knowledge-intensive and engineering teams.

Although being in multiple teams exposes individual members to new sources of knowledge that, when applied in a focal team, can improve its performance, it poses, at the same time, challenges for professionals in terms of time allocation, divided attention, attention switching and coordination especially if members are engaged in complex tasks (Speier et al., 2003) such as research and development and innovative activities.

First, as the number of multiple team memberships increases, the need to switch often between different projects may limit the time and the attention devoted to the needs of each specific project, eventually offsetting the benefits derived from the acquired knowledge diversity. Empirical evidence reinforces this argument. Tucker and colleagues (2007) show the importance of external knowledge to improve the implementation of new practices in hospital teams and they underline how a critical 
condition for a successful implementation of new knowledge is that learners have the opportunity to experiment with the new practice and to shape it. Also Bresman (2010) shows that external activities enacted by pharmaceutical $R \& D$ teams are valuable to increase the team performance. Examples of such activities are deriving lessons about the task through the observation of the work of others and identifying important practices. The author finds, however, that team performance improvements occur only when teams engage also in internal activities such as knowledge experimentation and reflection. It can be argued that in a MTM context these exploration activities can be successfully undertaken at intermediate levels of MTM, where team members can find occasions to reflect on the acquired knowledge, to experiment with it and eventually to modify it to fit with the specific focal team context, but become difficult to accomodate in the complex and fluctuating work schedules of teams operating at high levels of MTM.

In addition to that, as individuals increase their participation in multiple teams, they have to deal with multiple deadlines, interruptions, and frequent task switching (Perlow, 1999; Leroy, 2009) that, through the impact on professionals' attention, could affect negatively the performance of teams. Leroy's study (2009) shows that switching between tasks often entails the presence of attention residue, that is to say the tendency to keep thinking about a previous task (or, in the case of MTM, the previous project task) even when entering into a different project's task, with potential negative consequences on performance, especially for complex tasks like the ones involved in innovation and R\&D activities (Speier et al., 2003). Consistently, other empirical studies show us that switching between tasks generates costly cognitive interferences from a previous task to a current task that diminish the effectiveness of the latter (e.g. Altmann and Gray, 2008; Rubinstein et al., 2001). Finally, in terms of work coordination, the existence of numerous multiple teams where professionals are simultaneously engaged implies that by devoting time to one team, a professional's actions impact not only on that specific team, but also on the whole set of other teams whose work may need to be rescheduled or postponed with potentially negative consequences in terms of team outcomes.

All the above suggests that very low and very high levels of MTM will be more dysfunctional for team performance than intermediate levels of MTM. Thus, we first hypothesize that:

Hypothesis 1. The relationship between multiple team membership and team performance is curvilinear in the shape of an inverted $U$, such that teams whose members are, on average, engaged simultaneously in few or many teams experience lower performance.

\subsection{The moderating role of external advice receiving}

$R \& D$ professionals involved in a multiple team membership context are exposed to multiple sources of information and knowledge through formal organizational design. In addition to that, current theories of social networks highlight the importance of informal social interactions between organizational actors for exchanging valuable work-related resources and enhancing collaboration 
especially when individuals and teams engage in knowledge-intensive work (Cross and Parker, 2004; Sparrowe et al., 2001; Chung and Jackson, 2013). When professionals find social support within their organization, for instance, they are better at multitasking between different projects (Baer and Oldham, 2006). Through advice from colleagues, individuals in a team are given assistance and guidance that are related to the successful completion of work (Sparrowe et al. 2001). In addition, knowledge heterogeneity, derived from informal social networks, and its recombination, is particularly important to enhance innovative performance (Rodan and Galunic 2004). At the team level, extant research informs us that teams' ties with external parties are related to teams' positive outcomes such as improved supervisory appraisals, productivity and inventive performance (Ancona, 1990; Ancona and Caldwell, 1992; Oh et al., 2004; Reagans and Zuckerman, 2001; Wong, 2008; Bercovitz and Feldman, 2011; Chung and Jackson, 2013). Unfortunately, the above studies did not consider the fact that often team members span simultaneously multiple team contexts. Based on recent literature on social networks we argue that, for teams that operate in the unique context of MTM, external advice receiving affects the strengths of different processes (i.e. knowledge acquisition versus attention and coordination) for teams whose members operate at low and at high levels of MTM and, therefore, it will act as a moderator of the relationship between MTM and team performance.

Specifically, we anticipate that, at low levels of MTM, teams whose members can avail themselves of numerous advice relationships with people outside their teams (external advice receiving) attain higher performance, while at high levels of MTM, external advice receiving is associated with lower team performance. We base our reasoning on the following arguments. Previous studies on boundary-spanning activities support the idea that teams interpreting external activities (e.g. feedback seeking) as important for the team's life are rewarded with higher supervisory appraisal as compared to more isolated teams (Ancona, 1990; Ancona and Caldwell, 1992). Also Reagans and Zuckerman (2001) show that corporate R\&D teams with intense interactions between team members who hold diverse networks outside the teams attain better productivity. Supposedly, these connections help to bridge the external network's structural holes, bringing inside the teams diverse information and knowledge from outside members, thus creating the conditions for increased teams' performance. Finally, we know that group performance is enhanced in teams characterized by higher knowledge variety of its members that, in its turn, can be increased by importing new knowledge and viewpoints through a high range external advice network (Wong, 2008). Recently, the relationship between external informational network strength and team performance has been found stronger for teams characterized by non-routine tasks like science teams because of their higher and more complex information-processing demands (Chung and Jackson, 2013).

Overall, the previous arguments suggest that the access to informal external network ties results in the transfer of new information, advice and knowledge that have the potential to trigger positive consequences, because they provide individuals and teams with valuable information that would be more difficult to obtain through more formal means of communication. At low MTM, therefore, 
external advice receiving and MTM can act like complements. As a matter of fact, at low multiple membership, team members do not have access to various sources of perspectives, information and knowledge coming from memberships across teams. Receiving advice from the team external network can therefore supply the amount of external work-related information and knowledge that is likely to be relevant for team performance. A focal team's members involved in few project teams can commit themselves for longer periods of time to the same focal team and, as a result, bring into the team the amount of advice received, internalize it and incorporate it into the team activities and processes, with the likely consequence of improving team performance. Hence, at lower levels of MTM, as external advice receiving increases, multiple team membership becomes less influential in shaping increases in team performance.

We also contended that, at high levels of MTM, team performance will decrease as a consequence of attention and coordination issues and we argue that this relationship might also vary as a function of the amount of external advice receiving as this latter can be expected to increase issues of attention and further dampen the ability of teams to coordinate their activities. Two lines of evidence support this argument. On one hand, the MTM already provides for some information and knowledge diversity, making less necessary to resort to external social networks for advice and help. On the other hand, extant research tells us that social networks require a valuable resource, like time, to be managed and maintained (Day and Kilduff, 2003; Rodan and Galunic, 2004). At high MTM levels, the attention deficits can be severe and the need to manage the external advice relationships adds to the need of managing the multi-team environment and the switching between project boundaries, with a likely detrimental impact on team performance. In addition to that, high levels of MTM could deprive team members of the time to think about the usefulness and relevance of the additional external advice received for the specific project. In other words, team members could waste time and energies following many pieces of information and advice and be unable to focus on what is really valuable to the specific team.

In other words, as depicted in Figure 1, we hypothesize that:

Hypothesis 2. External advice receiving will moderate the inverted $U$-shaped relation between multiple team membership and team performance so that:

a) teams with high external advice receiving will exhibit higher team performance in response to low multiple team membership than those who score low on external advice receiving;

b) teams with high external advice receiving will exhibit lower team performance in response to high multiple team membership than those who score low in external advice receiving.

\subsection{The moderating role of instant messaging use}

Teams avail themselves of a variety of collaborative technologies (e.g. telephone, email, instant messaging systems, videoconferencing systems, to name just a few) to accomplish their tasks, to 
support collaboration and foster coordination, and to transfer information and knowledge among individuals and teams (e.g. Suh, 1999). Among the different collaborative technologies available in the workplace, IM is particularly useful for those workers who engage simultaneously in many knowledge intensive activities, tasks, and projects (Pazos et al., 2013; Bertolotti et al., 2012; Quan-Haase et al., 2005).

IM systems are designed to support different kinds of social interactions and, in the first stages of their diffusion, they were mainly used for personal interactions (e.g., interactions with friends). This is the main reason why many organizations opposed, and a few still do, the introduction of IM systems in the workplace. However, IM is now intensively used in the workplace. A recent survey on different companies reports that $73 \%$ of employees uses IM daily to interact with co-workers and clients and that, on average, individuals spend 41 minutes per day on IM, having 8 IM conversations per day with 5 different people (Radicati, 2012). On top of this, the heated debate on the extensive use of emails in organizations and its negative impact for individual and team outcomes (e.g. reduced productivity, increased stress, Taylor et al., 2008) is increasingly suggesting to consider other collaborative technology, like IM, as a primary tool for collaboration, especially in knowledge intensive contexts, such as R\&D teams (Tudor and Pettely, 2010; Treem and Leonardi, 2012). Unfortunately, most researches on IM relied on laboratory studies or focused on adoption and usage patterns (e.g. Nardi et al., 2000; Chung and Nam, 2007). Thus, we still know quite little about the consequences of IM use on organizations (Cho et al., 2005; Cameron and Webster, 2005; Pazos et al., 2013).

In work contexts, IM supports quasi-synchronous communication and allows for a combination of synchronous conversations and asynchronous use of text transcripts and document transfer with the potential to enable high immediacy of feedback (Cho et al. 2005; Maruping and Agarwal, 2004). Three structural features of IM are particularly useful in R\&D contexts characterized by high levels of MTM: polychronic communication, presence awareness, and silent interactivity (Dennis et al., 2010). Polychronic communication, i.e. the possibility of conducting multiple conversations in parallel, allows individuals in multiple teams to keep in touch simultaneously with co-workers from different teams. Polychronic communication refers both to simultaneous multiple IM conversations as well as the simultaneous use of IM and other communication technologies (Cameron and Webster, 2005). IM systems also indicate if users are connected and/or available, providing members with information on presence awareness. Such information is particularly useful when team members are not always colocated and need to know if others can or cannot be interrupted. The increased distribution of knowledge intensive work across national and organizational boundaries (e.g., Manning et al., 2008) is making this feature particular relevant. Finally, the silence of text-based IM allows individuals to contact or be contacted by team members without disrupting the physical workspace they are currently working in. To this regard, Dennis et al. (2010) describe the practice of 'invisible whispering' as the use of IM during meetings in order to interact both with meeting participants and external others. It is important to note that the three features of i) polychronic communication, ii) presence awareness, and 
iii) silent interactivity, are particularly relevant in MTM contexts where i) being engaged in multiple conversations is not infrequent; ii) knowing what your team members do is more difficult, given their multiple engagements, and iii) being involved in numerous project meetings can reduce the availability of individuals.

When describing the use of IM in the workplace, most literature seems to assume that individuals prefer to use IM only for brief interactions and mainly for coordinating or getting quick information that complements or facilitates interactions with other media (e.g. Nardi et al., 2000; Li et al., 2011). However, in-depth qualitative studies have revealed that IM is used in more nuanced and diversified ways in the workplace. If we just focus on empirical studies conducted in knowledge intensive settings or R\&D firms, we find that IM is most often used for long, intermittent interactions (Isaacs et al., 2000) and that team members use IM intensively for sharing knowledge (Bertolotti et al., 2012), collaborating on tasks (Isaacs et al., 2000), and solving problems together (Quan-Haase et al., 2005), i.e. for actually conducting their knowledge intensive tasks as a team, and not just for quick information gathering.

Given the extensive and diversified use of IM in R\&D settings characterized by high levels of multitasking, it is important to capture the interplay between IM use, MTM, and performance. Literature tells us that IM can bring both positive and negative effects on work related performance. For instance, IM systems allow for almost immediate access to co-workers and the development of both planned and spontaneous interactions, but because of their characteristics, they can increase disruptive interruptions in the workplace (Rennecker and Godwin, 2005). Based on recent literature on IM use and interruptions (e.g. Cho et al., 2005; Garrett and Danziger, 2007; Li et al., 2011; Pazos et al., 2013) we argue that the effect of average IM use in teams on the relationship between MTM and team performance varies according to the levels of MTM. Specifically, we suggest that at low levels of MTM, teams whose members make, on average, an intense use of IM attain higher performance while at high levels of MTM an intense use of IM is associated with lower team performance. We base our reasoning on the following arguments.

Intense use of IM supports work coordination in MTM contexts, allowing collaborators to ask questions, discuss task activities, and solve problems across teams. Rennecker and Godwin (2005) observe that the synchronous nature of IM allows for reduced delays in the execution of tasks. For instance, in a $R \& D$ project team whose members make on average an intense use of instant messaging, team members can communicate quickly that additional work, sometimes unexpected, is required and can quickly understand who is immediately available and reach individuals that are currently working on other teams. In other words, the interactions channeled by IM can fasten the execution of work and represent a precious source of knowledge and information that can be incorporated in better team outcomes (Zellmer-Bruhn, 2003; Ou and Davison, 2011). Unfortunately, when we look at the standpoint of receivers of interruptions (or information providers), large numbers of interruptions can become overwhelming (Rennecker and Godwin, 2005). However, at low levels of 
multiple team membership, teams whose members intensively use IM can still coordinate promptly their actions and efforts. Because of the few multiple memberships held by team members, each team can accommodate such coordination needs and even improve working relationships, enhancing their team performance (Cho et al., 2005, Ou et al., 2010). As an example, empirical evidence shows us that, at times, people employ collaborative technologies like instant messaging to manage strategically the timing of interruptions (Garrett and Danziger, 2007; Nardi et al., 2000). Teams where members hold few multiple memberships can easily negotiate conversational availability within and between teams increasing the opportunity for a satisfactory negotiation of the interruption timing. In addition, thanks to the feature of silent interactivity, teams whose members make an intensive use of IM can be continuously engaged in collaboration, even when some team members are involved in other meetings. This feature is particularly precious when R\&D teams approach deadlines (e.g., milestones, final deliveries).

Conversely, when the levels of MTM increase, while working in one project team, professionals will typically receive more requests via instant messaging from colleagues from many other project teams and will need to reach many different others in order to complete or integrate their own work. Numerous interruptions cause a frequent task switching that reduces the level of attention on individual tasks (Leroy, 2009). It often takes time and effort for team members to get back to speed up the project they have switched from (Leroy, 2009). When tasks are complex, like those carried on by knowledge professionals, task switching between different projects is detrimental to individual performance. As the complexity and diversity of tasks increase, the time required to cognitively reengage with a given team increases, thereby increasing the switching cost of transitioning between projects. Thus, a high level of interruptions, coupled with the necessity to shift back and forth between many different project teams, will make coordination cumbersome likely decreasing individual performance and thus affecting overall team performance.

When using IM in high MTM circumstances, team members will most probably experience situations where they need to simultaneously process information and knowledge received from one team and contribute their knowledge to another team, i.e. they will experience dual-task interference (Heninger et al., 2006). Heninger et al. (2006) demonstrated that dual task interference is associated to worse decision making in teams and speculated that such effect is particularly salient in situations that have more complex information competing for attention, like MTM scenarios.

Moreover, at high levels of MTM, an intense use of IM requires professionals to undertake multiple simultaneous and heterogeneous conversations and therefore reduces the opportunities for a negotiation satisfying all the involved parties (Johnson and Cooper, 2009), with negative consequences in terms of coordination of the activities within single teams and eventually team performance.

Finally, teams intensively using collaborative technologies should develop and share over time norms of use, otherwise the different expectations held by team members could hamper the 
functioning of the team (Gibson and Cohen, 2003). The hectic organization of work in presence of high levels of MTM can make more difficult for the members of each focal team to find occasions for discussing misunderstandings and negotiating norms for aligning behavioral expectations related to IM use, as compared to a situation of low MTM.

To summarize, we hypothesize the following moderated relationship (see Figure 1 for a representation):

Hypothesis 3. The use of instant messaging will moderate the inverted $U$-shaped relation between multiple team membership and team performance so that:

a) teams whose members, on average, make an intense use of instant messaging will exhibit higher team performance in response to low multiple team membership than teams whose members, on average, make a limited use of instant messaging;

b) teams whose members, on average, make an intense use of instant messaging will exhibit lower team performance in response to high multiple team membership than teams whose members, on average, make a limited use of instant messaging.

\section{Data and methods}

We conducted our study in the R\&D unit of a world-leading company in the alternative energy industry. In this unit, different professionals (e.g., electronic, mechanical, mechatronic engineers and technicians) are engaged with the research and development of advanced technological systems using alternative energy sources, such as LPG (liquefied petroleum gas) and CNG (compressed natural gas). The company is part of a large group and, at the time of data collection, held a reputation for being one of the most dynamic and innovative Italian medium-sized company. The R\&D members are employed simultaneously on different projects. Each project is devoted to the creation of a subsystem for a specific client (an OEM - Original Equipment Manufacturer) or for final customers (an After Market solution). A unique team of R\&D members carries out each project, i.e. each team is created anew at the beginning of each project and, although individuals work on multiple teams, there are not stable teams that work on more than one project. For this reason, from now on we will use the term teams to indicate project teams. Managers assign individual team members to teams; even though they try, whenever possible, to match projects characteristics with professionals' individual preferences, there is no self-selection of R\&D professionals. Each team incorporates competences from one or more of the following knowledge areas: mechanical, electronic, mechatronic, electrical and industrial. Usually, individuals share their knowledge areas with other team members. Team members do not have other individual assignments or job demands beyond the participation to the project teams.

To investigate the influence of MTM on team performance and the moderating effects of external advice receiving and the use of IM, we first conducted preliminary interviews with the VP for R\&D, four senior managers, and the human resource manager to better understand the context under study. 
Then, we developed a multi-section questionnaire that we submitted to all the 83 members of the R\&D unit. Since top management supported the study, all the questionnaires were returned. We assured respondents that their individual responses would be anonymous and used only for research purposes, and asked them to return the completed questionnaires directly to us instead of routing them through the organization. The average age of respondents was 34 years (s.d. = 7.3) and they had worked with the organization for an average of five years (s.d. $=5.5)$. Their professional tenure was, on average, 11 years (s.d. = 9.34). Our sample comprises 40 teams.

While we submitted the questionnaire, we also asked respondents to compile diaries recollecting all the project activities they performed during the previous workday (Perlow 1999). For each episode we asked respondents to specify the duration of each activity, the extent to which it was planned or not, the effects on work activities, and the actors involved.

Finally, while we relied on survey data to test the hypotheses, we also conducted follow up interviews with a project manager and an $R \& D$ engineer that aided us in further interpreting the results.

\subsection{Measures and reliability}

\subsubsection{Multiple team membership}

Management provided us with a list of open projects at the moment of the study. Respondents indicated all the projects in which they were simultaneously involved. The projects lasted on average 13 months (s.d. 7.3). In line with the suggestion of O'Leary et al. (2011), and the measure adopted by Cummings and Haas (2012) and Mortensen (2014), we measured multiple team membership for a focal project team as the average number of simultaneous team memberships held by the focal team's individual members. This kind of operationalization of MTM is what Kozlowski and Klein (2000) name a 'configurational unit property'. Configurational unit properties 'emerge from the characteristics, behaviors or cognitions of unit members - and their interactions - to characterize the unit as a whole' (page 373) and are the result of compilation processes. LeBreton and Senter (2007) observe that: 'compilation processes rest on the assumption that there are apparent differences between aggregated and non aggregated data. Therefore, it is not necessary that individual or lowerlevel data demonstrate consensus prior to aggregation' (page 817).

\subsubsection{External advice receiving}

External advice receiving captures, for each focal team, the amount of advice received from coworkers 1) not belonging to the focal team and 2) not belonging to other overlapping teams in which the focal team's members are currently involved. Stated differently, it measures the amount of advice members of the focal team receive by organizational actors currently not involved in the same projects. The questionnaire listed all the respondents. Initially, we assessed individual advice receiving in terms of amount of work-advice received by asking our respondents 'In the past six months, who came to you for advice or help on work related matters at least twice?' In particular, we computed 
team members' external advice receiving in terms of their indegree scores in the network (Borgatti et al., 2002; Freeman, 1978; Wasserman and Faust, 1994), considering only the ties from the external network, that is to say from non-team mates. The indegree score indicates an objective measure of advice receiving as it measures the number of people who declared they were reached by the focal actor to whom they offered work-related advice. For each team, we then measured the external advice receiving as the total number of a focal team's indegree ties divided by the total number of possible ties.

\subsubsection{Average use of instant messaging}

To measure the use of instant messaging systems, respondents answered the following question: 'With what frequency do you use instant messaging (for instance skype) for work related purposes?' on a 1 to 4 points scale, where $1=$ monthly, $2=$ =weekly, $3=$ daily, $4=$ several times a day, with the non-use of the technology to be coded as 0 . We defined this scale based on the insights derived during the preliminary interviews with our informants. Specifically, at the time of the study the organization did not have collaborative technology policies, but allowed for the use of any IM system (although Skype prevailed as the most used system for text exchanges). Individuals were not encouraged neither discouraged in the use of IM, so the actual use reflected emergent individual practices and preferences and resulted in very heterogeneous behaviors (i.e. from a sporadic monthly use to an intense everyday use). For each focal team we calculated the mean value of the individual members' IM use. As for our measure of MTM, this operationalization reflects a configurational property and we do not expect agreement among team members. Indeed, consistent with Chan's (1998) additive model, this variable does not capture the perception of how IM is used in a team (that would be a composition variable), but how much, on average, team members use IM in a focal team.

\subsubsection{Team performance}

To collect measures of team performance we asked the R\&D unit VP to assess each of the project teams on four items (completing work on time, completing work within budget, satisfaction of the client with the quality of team output, and overall performance) that were the most relevant to the management view of R\&D team performance. We employed a seven-point scale ranging from "very poor" (1) to "outstanding”(7). Cronbach's alpha was equal to 0.9 .

\subsection{Control variables}

Empirical evidence informs us of the many variables that predict team performance. Therefore, we included several control variables to account for the variety of team membership, i.e. 'the diversity that characterizes the teams that individuals are members of' (O'Leary et al., 2011, p. 464), in terms of size, tenure, localization, knowledge areas, importance, task complexity, and average use of emails.

Specifically, our teams varied considerably in size. It is therefore important to control for the team size (Reagans and Zuckerman, 2001) that we measured as the number of professionals belonging to the focal team. 
R\&D professionals also varied in terms of the number of years they worked for the company. Following Chung and Jackson (2013), we included as a control the average team tenure that we calculated as the mean value of the organizational tenure of the focal team's individual members.

Teams whose members are co-located or delocalized in different sites can develop different social processes and adopt different ways to reach decisions. The localization of teams can therefore be an important variable in explaining their performance. We coded localization as a two-level variable $(0=$ all team members are co-localized; $1=$ some members in a team are de-localized $)$.

Teams differ in terms of the number of knowledge areas of their members (more specifically, mechanical, electronic, mechatronic, electrical and industrial) and this variable has been related in previous studies to team performance (Cummings and Haas, 2012). We measured the number of knowledge areas as the unique number of areas that individuals on a focal team indicated.

Teams whose members consider the focal project as the most important in their portfolio of activities and commit to it a higher percentage of time can benefit from increased attention to devote to that project (Maynard et al., 2012). The more people are in this condition, the more the project can benefit from intense contributions. We therefore controlled for the number of members who declared that each specific team was the most important in terms of dedicated time. For each focal team we calculated an index of 'importance' in terms of number of declared preferences divided by the team size.

Our teams carry out different types of projects. According to the managers we interviewed, Original Equipment Manufacturing projects (OEM) are complex projects where teams partner with global car manufacturers to develop new and innovative products. Conversely, the After Market projects (AM) are mainly devoted to personalize the already existing products, according to specific requests advanced by clients. These types of projects are deemed to be of lower complexity. Projects entailing both OEM and AM features were deemed as the most complex. Thus, project complexity was coded as a three-level variable (1=AM; $2=\mathrm{OEM} ; 3=\mathrm{AM} / \mathrm{OEM})$.

Finally, team members made use of other communication technologies for work-related purposes. Given the reported importance of email use and consistent with Ou and Davison (2011), we controlled in our model for the use of emails. Consistent with the scale on IM use, respondents were asked to answer the following question: 'With what frequency do you use emails for work related purposes?' on a 1 to 4 points scale, where $1=$ monthly, $2=$ weekly, $3=$ daily, $4=$ several times a day. For each focal team we calculated the average value of the individual members' email use.

\subsection{Data Analysis}

Hierarchical multiple regression analyses were used to test the hypotheses of quadratic/linear-Multiple Team Membership-by-linear- External Advice Receiving and Average Use of Instant Messaging interaction effects on the dependent variable of Team Performance (cf. Aiken and West, 1991; Cohen 
and Cohen, 1983; Janssen, 2001). Following Cohen et al. (2003), we standardized all the independent variables and the control variables to facilitate testing of quadratic and interaction effects.

To test the hypothesized interactions between Multiple Team Membership and External Advice Receiving/Average Use of Instant Messaging and their effect on Team Performance, we followed the steps taken by Janssen (2001).

\section{Results}

Table 1 presents a correlation matrix and descriptive statistics for all the measured variables. Teams are composed on average of 6.38 members, but team size varied from 2 to 27. It is interesting to notice that size was not correlated neither to team performance nor to MTM. On the other hand complexity is positively correlated to size, suggesting that larger teams are associated to more complex projects. On average, teams had a MTM of 8,92 ${ }^{1}$, supporting the fact that MTM is very relevant for this organization and its teams. In terms of collaborative technology use, it is relevant to notice that all teams use intensively emails, while they are more diversified in their use of IM.

Insert Table 1 about here

Table 2 reports the analyses for the inverted U-shaped relationship between Multiple Team Membership and Team Performance and for the moderating role of External Advice Receiving and Average Use of Instant Messaging on such relationship. ${ }^{2}$

Entering the control variables of Team Size, Average Tenure, Localization, Project Complexity, Importance, Number of Knowledge Areas and Average Use of Emails into the regression did not generally produce significant effects on Team Performance. In Step 2, we entered the main effect of Multiple Team Membership, which was not a significant predictor of Team Performance. Following, in Step 3, we entered the quadratic term of Multiple Team Membership, which was a significant predictor of Team Performance: $\left(\Delta \mathrm{R}^{2}=.13, \mathrm{p}<.05\right)$. In other words, there is an inverted U-shaped relationship between Multiple Team Membership and Team Performance, supporting Hypothesis 1. The value of MTM corresponding to the highest level of performance is about 9. It is interesting to note that our qualitative interviews largely support this result and clarify the challenges entailed in working in MTM scenarios. For instance, one of our informants told us that working on multiple projects, characterized by urgencies and the need for immediate attention, made it difficult for engineers to organize their time the way they preferred or to optimize their efforts across multiple

\footnotetext{
${ }^{1}$ To be sure that projects were carried out simultaneously and not sequentially, we analyzed diaries data and found out that, on the days the diaries were filled in, at least $70 \%$ of the open projects had one or more team members working on them.

${ }^{2}$ We used the variance inflation factor (VIF) to assess multicollinearity. The maximum VIF was 5.7 and the average VIF was 3.2. Therefore, we do not have reasons to suspect that multicollinearity was a problem.
} 
projects. Another informant told us that when you work on many heterogeneous projects it is very challenging to continuously switch from one to another:

The problem is that when you work on several projects they likely are different-some pure development, others pure innovation for instance. It's impossible to manage well so many projects of different kinds! Some projects need concentration; the others need availability!

From the interviews and the diaries, the issue of MTM resulted as conceptually different from overload (although, of course related). For instance, analysing the data from our diaries, we did not find that people needed to work a significant amount of extra hours (on average they worked 8 hours per day, with a standard deviation of 25 minutes), supporting the idea that was MTM, and not work overload, to drive the dynamics we depict.

In Step 4 of our regression model, External Advice Receiving and Average Use of Instant Messaging were entered, but were not predictive of team performance.

In Steps 5 and 6 we added, respectively, the interactions of Multiple Team Membership and External Advice Receiving/Average Use of Instant Messaging. Both interaction terms were found significant for Team Performance $\left(\Delta \mathrm{R}^{2}=.09, \mathrm{p}<.05\right.$ and $\left.\Delta \mathrm{R}^{2}=.07, \mathrm{p}<.05\right)$. Finally, in steps 7 and 8 we entered the quadratic-by-linear interactions of Multiple Team Membership and External Advice Receiving/Average Use of Instant Messaging; while the former term was significant ( $\Delta \mathrm{R}^{2}=.08$, $\mathrm{p}<.05$ ), the latter was non-significant. As can be seen in Figure 2, the inverted U-Shaped relationship between Multiple Team Membership and Team Performance is moderated by External Advice Receiving, such that when multiple team membership is low, External Advice Receiving has a positive effect, when multiple team membership is intermediate, External Advice Receiving has a negative effect and, at very high levels of MTM, External Advice Receiving becomes again beneficial for the performance of the focal team. Hypothesis $2 \mathrm{a}$ is therefore supported, while hypothesis $2 \mathrm{~b}$ is not supported. Figure 3 shows that the inverted U-shaped relationship between Multiple Team Membership and Team Performance is moderated by the Average Use of Instant Messaging so that when multiple team membership is low, IM use has a positive effect and when multiple team membership is high, it has a negative effect. Thus, Hypotheses $3 \mathrm{a}$ and $3 \mathrm{~b}$ are supported ${ }^{3}$.

Insert Table 2, Figure 2 and Figure 3 about here

\footnotetext{
${ }^{3}$ Given the small number of our observations in relation to the number of our predictors, we performed a power analysis with the software G*Power 3.1 (Faul et al., 2007, 2009). The power test of the regression with our hypothesized relationships reports a post hoc power level of 0.8 , which may indicate an adequate sample size for the variance explained and number of predictors in the model (Cohen, 1988, 1992). However, it is important to acknowledge that there is a debate on the usefulness of this kind of analysis (e.g., Hoenig and Heisey, 2001), especially when results are significant (Cohen, 1992). In order to further check for the robustness of our findings we re-run our model without control variables (thus reducing the number of predictors). This reduced model is significant $(\mathrm{F}=3,89 ; \mathrm{p}<.05)$ and the difference between this model and our final model in table 2 is not statistically significant $\left(\Delta \mathrm{R}^{2}=.20\right.$, n.s.). This suggests that having a larger number of predictors does not significantly reduce the power of our analysis.
} 
With reference to Hypothesis $2 b$, our quantitative data show that there are three projects with MTM higher than 12 and, in this condition, differently from what we hypothesized, having high levels of external advice receiving has a positive effect on performance (see figure 2). During follow up interviews we asked a manager and an engineer to comment upon this specific finding. The two provided similar explanations and the manager presented his perspective with the following words:

The fact is that there are projects where team members are split among too many different projects [...] They [individuals in teams with high MTM] struggle to carry on the activities of one single project. They really need the help or suggestions of other people to finish or even do their work. People in their project cannot do that - they are split in the same way - so they go out, they ask for others' support... Sometimes we even avail ourselves of external consultants in order to fill this gap.

This excerpt suggests that at very high levels of MTM team members may not be able to complete their tasks without the help of coworkers. Given that all team members are likely involved in numerous other projects, they need to resort to the help of external trusted others, whose work-related support is implemented straightforwardly into team activities and practices.

In relation to the last hypothesis, during an interview, the VP for R\&D told us that IM was a technology that the company was exploring for addressing the issue of email overload. In his words 'People here use email too much and for the wrong purposes. Instead of using email as a collaborative tool, people use it to document their own choices and to justify themselves when problems arise. They say: 'But I told you on an email on date...'. In his perception (and consistently with previous literature, Taylor et al., 2008) emails determined information overload and a collective lack of responsibility. On the other hand, IM was perceived as a possible alternative for collaboration in teams. However, our evidence points out that IM interacts with MTM levels. While its use enhances performance at low levels of MTM, at high levels of MTM negative effects arise. When working on a high number of projects, 'the computer screen becomes like a merry-go-round of colors and signals', one engineer told us, because of the high number of open chats. A project manager, engaged in a large number of projects told us:

At the beginning of my working day I try to plan my work. First of all, I need to understand what my priorities are. I cannot define those priorities on my own, but I need to orchestrate them with my colleagues. This is where Skype plays a major role. However, as the day passes, requests increase and new colleagues from different projects log in and ask new things. I cannot avoid responding them, because we are in the same team or, well, we are on the same boat anyway. I end up feeling bad because I cannot really attend to the request of everyone. Sometimes I even feel rude if I don't respond. [...] When everyone on a team has similar experiences, we have real problems...

The field note above, that reflects an individual strategy, suggests that when these kinds of strategies coalesce at the team level, they can produce detrimental effects in terms of team performance. 


\section{Discussion}

\subsection{Theoretical contributions}

Our study contributes to the current scholarly conversation that advocates the necessity to incorporate into models of team effectiveness the structural, technological and social changes that organizational teams are experiencing today such as, for instance, the need to work simultaneously on multiple project teams and the subsequent fluidity of membership, the enhanced recourse to collaborative technologies to manage an increased distribution of work, and the changing nature of collaboration (e.g. Wageman et al., 2012b).

We show that these new configurations of work teams matter for team performance, especially in knowledge-intensive settings. In particular, we investigated the inverted U-shaped relationship between Multiple Team Membership and team performance (Hypothesis 1). Further, we proposed that this relationship is moderated by the external advice received (Hypothesis $2 a$ and $2 b$ ) and by the average use of collaborative technologies -in particular instant messaging- made by team members (Hypothesis 3a and 3b).

In relation to Hypothesis 1, our findings are consistent with the theoretical model of O'Leary and colleagues (2011) who propose the existence of an inverted curvilinear relationship between MTM and team productivity. Our evidence therefore offers an empirical validation of the model and extends it to the analysis of a different team outcome, that is to say team performance. Investigating team performance, and not only productivity, is highly significant for R\&D contexts. In R\&D units and innovative organizations, it is not only important to gain high productivity (i.e. to use resources efficiently), but also of particular relevance to obtain outcomes of high quality and that satisfy clients. To make an example, while productivity is of course relevant for a new product development team, managers are especially interested in the results the team is able to produce. Thus, understanding how MTM affects performance, in addition to productivity, becomes of paramount relevance.

Our results, on the surface, seem inconsistent with the recent empirical evidence offered by Cummings and Haas (2012) who found a positive relationship between MTM and team performance, without any inflection point. However, a closer look at the data highlights that their teams experienced a maximum level of MTM lower than the inflection point of the curvilinear relationship that we found in our sample. Stated differently, the organization studied by Cummings and Haas assigned its employees to work concurrently on a lower number of multiple teams overall. However, since innovative contexts are characterized by increasing levels of MTM, we expect a context like the one we studied to become more commonplace than in the past. 
Our results further expand our knowledge about the importance of social networks in the workplace. While previous research has already emphasized the role of external team informal networks and conceptualized social networks characteristics as exerting a direct effect on team processes and team performance (e.g. Henttonen, 2010; Chung and Jackson, 2013), it did so without paying attention to the fact that often team members span multiple team contexts simultaneously. We enrich this stream of literature suggesting that in these new forms of team work, external team informal networks may play an important moderating role. In particular, we advance the argument that to enable teams operating in a MTM context to apply productively the work-advice coming from outside the team boundaries, the access to advice and informational resources should 'match' the team level of MTM. We thus contribute to a recent stream of studies on social networks and multitasking (Schultz et al., 2013; Aral et al., 2012) that recognizes, beyond the obvious informational benefits, the costs entailed in the maintenance of large external networks and knowledge processing, especially in multitasking and multi-team contexts where professionals are already compelled to switch between various activities according to situational demands. For instance, Schultz and colleagues (2013) studied the moderating effect of external networks on the relationship between individual multitasking (switching among $\mathrm{R} \& \mathrm{D}$ and operational tasks) and individuals' $\mathrm{R} \& \mathrm{D}$ performance to find that multitasking individuals did not benefit from access to external networks as much as their focused colleagues because they were unable to transform in an effective way these relational resources into R\&D outputs. As emphasized by the authors, the additional networks activities may overstrain these employees (2013:1363).

Our research complements these studies (conducted at the individual level) by moving to the team level. Also in our theorizing of the MTM-Team performance relationship, the external advice networks play a moderating role because they should compensate for missing knowledge. At a team level of analysis, we anticipated the positive and negative effect of high levels of team external advice receiving for low and intermediate levels of MTM. However, the result that we obtained for high levels of MTM was unexpected. A plausible explanation is that when MTM becomes extremely high, individuals in a team are faced with the challenge of being in a project where everyone's resources are extensively taxed by the belonging to many teams simultaneously and likely temporal misalignments would make difficult some sort of team coordination. In such situations, team members would probably be unable to reach teams' goals without resorting to external help. While we could not distinguish, with our quantitative data, the 'type' of help and advice that teams searched for, our follow up interviews suggest that the nature of what is sought changes from low to high levels of MTM passing from an exploratory search for advice to a direct help for specific problem solving. At high levels of MTM successful teams need external individuals to help them more practically in carrying out their work. They not only need advice in the form of tips and suggestions, but also need practical help in completing their work. Our interviews suggest that, sometimes, this form of help comes from external consultants who are hired to help out some teams in their work. The long-term 
effect of these types of behaviors on individuals' and teams' ability to incorporate external knowledge into team processes calls for future investigation.

Finally, we enrich our understanding of the consequences of collaborative technology use in organizations adopting new forms of team work. Previous works have proposed that the use of collaborative technology interacts with other operational and social processes in teams (e.g. conflict, affect), affecting their performance (e.g. Maruping and Agarwal, 2004). Our work extends this line of research by focusing on IM and its interaction with MTM. Given its distinctive features (polychronic communication, presence awareness, and silent interactivity), IM is increasingly used in R\&D settings because it can help not only team members in attaining better coordination (e.g. by scheduling impromptu meetings or signaling awareness), but it can also support the fast dissemination of information and knowledge within and across teams (e.g. by actually supporting collaborative practices, e.g., Quan-Haase et al., 2005). In addition, IM is considered a possible alternative to collaborative technology, like email, that is perceived as particularly intrusive and overwhelming in the modern workplace (Taylor et al., 2008). Our results, however, show that the usefulness of IM is contingent to the specific work scenario and that IM can favor or hamper professionals' teams thriving in multiple team membership scenarios. We found that the extent to which R\&D teams utilize IM systems moderates the relationship between MTM and team performance. Specifically, in teams characterized by low levels of MTM, individuals are able to accomplish the benefits of an intense use of IM as a facilitator of knowledge sharing and coordination. Unfortunately, at high levels of MTM, competing mechanisms of attention, i.e. deficit and dual task interference, come into play leading teams whose members make intense use of instant messaging to attain lower performance. Our qualitative evidence supports the idea that, when MTM increases, individuals in teams are probably going to receive more requests and ask more information over the IM, thus fragmenting their everyday work flow to an extent that becomes detrimental for both individual and team performance. Indeed, this result is mostly significant for R\&D contexts, where fragmentation of knowledge intensive work is particularly detrimental to performance, but less for more routine-like contexts, where interruptions through collaborative technology are not deemed as negative (Speier et a., 2003).

\subsection{Managerial implications}

Our work offers insights particularly valuable for managers operating in the context of innovation, where the possibility to access multiple sources of knowledge -provided, for instance, by MTM scenarios- can lead to increased creativity and novel solutions (Hargadon and Sutton 1997) but makes, at the same time, organizational units and team functioning more complex.

Building on our findings, we propose that managers looking to attain high levels of R\&D team performance in a MTM scenario should take into consideration, among others, the following variables: (1) the number of teams professionals are simultaneously involved in and the subsequent MTM of the focal teams, (2) the workplace social networks, (3) the use of collaborative technologies. Knowing 
how these factors influence team performance could allow better team design decisions and more conscious use of organizational and personal resources such as advice networks and instant messaging.

In relation to the first point, according to our research, managers should consider that MTM scenarios are not necessarily good or bad for organizations but must be carefully managed. Some levels of multiple membership benefit R\&D teams because of the variety of stimuli that professionals can be exposed to and that can cross team boundaries improving the functioning of single teams. However, such benefits cannot increase endlessly and after a certain level of multiple memberships the cognitive effects of allocating time across teams and the need to span diverse team contexts can impose costs leading progressively to diminished team performance.

In relation to advice receiving, at intermediate levels of MTM a focal team's members - already endorsed with sources of knowledge coming from the membership in other teams- could waste time and energies following many pieces of information and advice coming from the additional external social networks and thus be unable to focus on what is really valuable to the specific team. A managerial implication of this finding is that prompting professionals engaged in an intermediate number of teams to focus on a smaller number of critical relationships can help single teams to balance the need to resort to external advice networks and the resources needed to manage large networks. On the other hand, at low and high levels of MTM managers should stimulate the recourse to external relationships. At very high levels of MTM another strategy could be to add resources to teams, in order to reduce MTM and the need to be helped by external colleagues.

Managers and team leaders, while choosing the collaborative technologies to support their R\&D teams, should take into account not only the specific characteristics of single projects but also the whole portfolio of projects in which team members are involved. Specifically, we propose that managers should create awareness on the level of MTM of single projects and should promote a netiquette consistent with an intense use of IM only in teams characterized by low levels of MTM.

\subsection{Limitations and Future Research Directions}

While we believe this research contributes to theory and practice, it is not without limitations. First, our work was conducted with a limited number of teams and in a single organization with some specific characteristics. Of course future research would benefit from an investigation conducted in a larger sample of teams. In addition, to better explore the relationships between MTM, team performance, social networks and collaborative technology use it might be valuable to consider other contexts (e.g. different industries) and organizational units (e.g. operations). For instance, the nature of the R\&D activities carried out by our organization requires professionals to work in month-long projects. Long term projects make team membership less transient and this has been associated to a stronger relationship between shared experiences of actions/reflections and team performance (e.g. Van der Vegt et al., 2010). Moreover, the nature and effect of the interruptions generated by networks 
and technology use could be different if compared to other teams that must deliver their outputs within weeks or even shorter periods of time. Future research would therefore benefit from an analysis of both long and short-lived project teams. Also, in this organization teams varied significantly in terms of size that was, in its turn, positively correlated to the complexity of projects. Literature suggests that as size increases, team members may have limited contacts that would make sharing information and coordination more difficult, thus influencing team performance. In our model, though, team size was not associated neither to performance neither to MTM. These findings suggest that, in our context, the 'external' coordination costs associated to MTM have played a major role in affecting performance, while 'internal' coordination costs have not. Does this apply to other contexts? Future research should investigate the interplay between size, MTM, and project complexity.

Second, our organization imposes, on average, a high level of MTM to its R\&D professionals. This is partly driven by the fact that the company strictly follows the timetable set up by clients and, therefore, to optimize the use of resources and to limit waiting-time, it imposes an extreme multitasking. At the same time, it is a highly prestigious organization in Italy. It is plausible to think that professionals were willing to accept this extreme MTM context to be able to make a work experience in this organization. What would happen to organizations perceived as less prestigious? How would professionals react to such extreme multitasking situation and what would be the impact on team performance?

Third, another potential limitation refers to our performance measure. In order to avoid common method bias we asked the management to rate team performance. Of course, we obtained a single evaluation (for the different dimensions of performance of each team) that may have been influenced by leader's perceptions and interpretations. Thus, an alternative interpretation of our evidence could be that, rather than actual performance, MTM affects the managerial perception of team performance. We believe that in this context managerial ratings reflected an objective evaluation because management was fully in charge of dealing with clients and supervising time and budget. However, future studies could use more comprehensive measures of team performance including, for instance, team members ratings (e.g., Mortensen, 2014), clients evaluations (Carson et al., 2007), and objective measures taken from organizations' management information systems (Gupta et al., 2009).

Fourth, our paper focused on the use of IM because its quasi-synchronous features and likely "polychronic" use make it suitable to R\&D contexts. However organizations and R\&D units are increasingly adopting new collaborative technologies that integrate different networking capabilities. Examples are enterprise collaborative systems that make use of different social networking tools, blogs and wikis. It would be interesting to expand our work and analyze the combined effect of MTM and advanced collaborative technologies. Moreover, it would be interesting to focus on the effects of individual strategies in the use of technologies, for instance on how much different strategies for managing IM are in conflict within single teams and affect performance in relation to MTM scenarios. To this regard, another likely moderator worth of investigation, beyond the use of collaborative 
technology, could be the variance in team members' perceptions about the usefulness of the technology because differing perceptions could lead to differing behavioral expectations that, in turn, could impair team functioning.

Finally, in our study we privileged the investigation of external social networks and IM use as possible moderators because recent contributions outline how the implementation of the changed and complex work settings like the ones characterized by multitasking and MTM scenarios is inextricably linked to an increase in the information flows and interactions that can occur through various types of technology in different places and times (Tennenbaum et al. 2012, Aral et al. 2012). Moreover, these variables are particularly salient for knowledge intensive and $R \& D$ activities that are nowadays more and more conducted in a distributed fashion (Manning et al. 2008). Consistent with the suggestions of O'Leary and colleagues (2011), we recognize that our model and future research in MTM contexts could greatly benefit from the investigation of the role plaid by individual differences on managing work-time on the MTM-Performance relationship. Specifically, the team members' preference to work on different tasks at the same time, or polychronicity (Bluedorn et al., 1999), is likely to play a moderating role in the above relationship. As a matter of fact, individuals may vary greatly in terms of their preferences for focusing on one task at a time (highly monochronic) or working on many things at once (highly polychronic). High levels of individual polychronicity, as opposed to low levels, seem coherent with contexts where professionals are asked to joggle and hoop between several projects even within a single work day (Cotte and Ratneshwar, 1999). Teams composed in large part by polychronic individuals, as opposed to teams characterized by a higher variance of team members' individual polychronicity, could benefit, in terms of effort and attachment, from the perception of higher fit between their and the organizations' preferences for managing work time, with likely positive consequences on single teams performance. The same polychronic individuals could be more willing - and more able - to accommodate the various coordination needs expressed by members of several teams fostering positive outcomes. We therefore believe that integrating individual and team level variables into a multi-level model of team effectiveness in new multitasking scenarios would bring interesting insights to both the literatures on time management and on temporal issues in team effectiveness.

\section{Conclusions}

As organizations' achievements depend more and more on the work of knowledge-intensive teams, the comprehension of the way they function and how to improve their performance is becoming increasingly important. The current research contributes to the team literature by providing empirical evidence on previously under-explored correlates of team performance, adding to the very recent literature that aims to understand how new ways of organizing based on multiple team membership influence the performance of individuals, teams and finally organizations. To our 
knowledge, this is one of the few empirical studies to investigate multiple team membership in conjunction to team performance. Our work sheds also new light on the role of external advice receiving and collaborative technologies like instant messaging as moderators of such relationship. Because multitasking and multiple-projects scenarios are becoming progressively commonplace, we believe that these results are especially important for project-based organizations that increasingly ask their knowledge workers to switch between several activities and work contexts.

\section{Acknowledgements}

This research was funded by the Italian Ministry of Research through the PRIN project 'International Sourcing of Knowledge: Organizational Factors and System Effects'. We would like to thank Mark Mortensen and Michael O’Leary for their constructive comments on earlier versions of this article.

\section{References}

Adecco, 2014. The traditional vs the modern workplace, Retrieved May $2^{\text {nd }}, 2014$, http://www.adecco.co.uk/news/traditional-vs-modern.aspx

Aiken, L.S., West., S.G., 1991. Multiple regression: Testing and interpreting interactions. Sage, Beverly Hills, CA.

Altmann, E. M., Gray, W. D., 2008. An integrated model of cognitive control in task switching. Psychological Review 115 (3), 602-639.

Ancona, D.G., 1990. Outward Bound: Strategies for Team Survival in an Organization. The Academy of Management Journal 33(2), 334-365.

Ancona, D.G., Caldwell, D.F., 1992. Bridging the Boundary: External Activity and Performance in Organizational Teams. Administrative Science Quarterly 37 (4), 634-665.

Aral, S., Brynjolfsson, E., Van Alstyne, M., 2012. Information, technology, and information worker productivity. Information Systems Research 23 (3) part 2, 849-867.

Baer, M., Oldham, G.R., 2006. The curvilinear relation between experienced creative time pressure and creativity: Moderating effects of openness to experience and support for creativity. Journal of Applied Psychology 91(4), 963-970.

Bercovitz, J. Feldman, M., 2011. The mechanisms of collaboration in inventive teams: Composition, social networks, and geography. Research Policy 40, 81-93.

Bertolotti, F., Mattarelli, E., Prencipe, A., Gupta, A., 2012. Perceived Modularity: A case Study of a Globally Distributed Team, Proceedings of the International Conference on Information Systems, ICIS 2012, Orlando (FL), United States, 16-19 December, Vol.4, 3347-3360.

Bertrand, M., 2014. Why Office Collaboration Is Essential in the Modern Workplace. Retrieved May 15th 2014, http://technologyadvice.com/human-resources-software/blog/office-collaborationessential-modern-workplace/

Bluedorn, A.C., Kalliath, T.J., Strube, M.J., Martin., G.D., 1999. Polychronicity and the inventory of polychronic values: The development of an instrument to measure a fundamental dimension of organizational culture. Journal of Managerial Psychology 14(3/4), 205-230.

Borgatti, S.P., Everett, M.G., Freeman, L.C., 2002. Ucinet for Windows, version 6.0: Software for Social Network Analysis. Analytic Technologies, Harvard, MA. 
Bresman, H., 2010. External Learning Activities and Team Performance: A Multimethod Field Study. Organization Science 21(1), 81-96.

Cameron, A. F., Webster, J., 2005. Unintended consequences of emerging communication technologies: Instant Messaging in the workplace. Computer in Human Behavior 21, 85-103.

Carson, J.B., Tesluk P.E., Marrone J.A. 2007. Shared leadership in teams: an investigation of antecedent conditions and performance. Academy of Managent Journal 50, 1217-34.

Chan, D., 1998. Functional relations among constructs in the same content domain at different level of analysis: a typology of composition models. Journal of Applied Psychology 83 (2), 234-246.

Chan, K.-Y., 2014. Multiple Project Team Membership and Performance: Empirical Evidence from Engineering Project Teams. South African Journal of Economic and Management Sciences, 17 (1), 76-90.

Cho, H.-K., Trier, M., Kim, E., 2005. The Use of Instant Messaging in Working Relationship Development: A Case Study. Journal of Computer-Mediated Communication. doi: 10.1111/j.1083-6101.2005.tb00280.x.

Chudoba, K., Watson-Manheim, M.B., 2007. Exploring the Virtual Work Environment: A Process Perspective. A.J. Salazar, Sawyer, S., eds. Handbook of Information Technology in Organizations and Electronic Markets, World Scientific, Singapore.

Chung, Y., Jackson, S.E., 2013. The Internal and External Networks of Knowledge-Intensive Teams The Role of Task Routineness. Journal of Management 39 (2), 442-468.

Chung, D. Nam, C. S., 2007. An analysis of the variables predicting instant messenger use. New Media \& Society 9 (2), 212-234.

Cohen, J., 1988. Statistical Power Analysis for the behavioral sciences, $2^{\text {nd }}$ ed. Erlbaum, Hillsdale, NJ.

Cohen, J., 1992. Statistical Power Analysis. Current Directions. Psychological Science 1 (3), 98-101.

Cohen, J., Cohen, P., 1983. Applied multiple regression/ correlation analysis for the behavioral sciences. Erlbaum, Hillsdale, NJ.

Cohen, J., Cohen, P., West, S.G., Aiken, L.S., 2003. Applied multiple regression correlation analysis for the behavioral sciences, 3rd ed. Erlbaum, Hillsdale, NJ.

Cohen, S.G., Bailey, D.E., 1997. What Makes Teams Work: Group Effectiveness Research from the Shop Floor to the Executive Suite. Journal of Management 23(3), 239-290.

Cotte, J., Ratneshwar, S., 1999. Juggling and hopping: what does it mean to work polychronically? Journal of Managerial Psychology 14(3-4), 184-205.

Cross, R., Cummings, J.N., 2004. Tie and Network Correlates of Individual Performance in Knowledge-Intensive Work. The Academy of Management Journal 47(6), 928-937.

Cross, R., Parker, A., 2004. The Hidden Power of Social Networks: Understanding How Work Really Gets Done in Organizations. Harvard Business School Press, Boston, USA.

Cummings, J.N., 2004. Work Groups, Structural Diversity, and Knowledge Sharing in a Global Organization. Management Science 50(3), 352-364.

Cummings, J.N., Haas, M.R., 2012. So many teams, so little time: Time allocation matters in geographically dispersed teams. Journal of Organizational Behavior 33, 316-341.

Day, D. V., Kilduff M., 2003. Self-monitoring personality and work relationships: Individual differences in social networks. M. R. Barrick, A. M. Ryan, eds. Personality and work: Reconsidering the role of personality in organizations. Jossey-Bass, San Francisco, 205-228.

Dennis, A. R., Rennecker, J. A., Hansen, S., 2010. Invisible whispering: restructuring collaborative decision making with Instant Messaging. Decision Sciences 41 (4), 845-886. 
Faul, F., Erdfelder, E., Lang, A.-G., Buchner, A., 2007. G*Power 3: A flexible statistical power analysis program for the social, behavioral, and biomedical sciences. Behavior Research Methods 39, 175-191.

Faul, F., Erdfelder, E., Buchner, A., Lang, A.-G., 2009. Statistical power analyses using G*Power 3.1: Tests for correlation and regression analyses. Behavior Research Methods 41, 1149-1160.

Ferriani, S., Cattani, G., Baden-Fuller, C., 2009. The relational antecedents of projectentrepreneurship: Network centrality, team composition and project performance. Research Policy 38, 1545-1558.

Freeman, L.C., 1978. Centrality in social networks conceptual clarification. Social Networks. 1(3) 215-239.

Garrett, R.K., Danziger, J.N., 2007. IM = Interruption Management? Instant Messaging and Disruption in the Workplace. Journal of Computer-Mediated Communication 13(1), 23-42.

Gersick, C.J.G., Hackman, J.R., 1990. Habitual routines in task-performing groups. Organizational Behavior and Human Decision Processes 47(1), 65-97.

Gibson, C. B., Cohen S. G., 2003.Virtual Teams That Work: Creating Conditions for Virtual Team Effectiveness. Jossey Bass, San Francisco.

Gupta, A., Mattarelli, E., Seshasai, S., and Broschak, J., 2009. Use of Collaborative Technologies and Knowledge Sharing in Co-located and Distributed Teams: Towards the 24-Hour Knowledge Factory. Journal of Strategic Information Systems 18 (3), 147-161.

Hansen, M.T., 1999. The Search-Transfer Problem: The Role of Weak Ties in Sharing Knowledge across Organization Subunits. Administrative Science Quarterly 44(1), 82-111.

Hansen, M.T., Haas, M.R., 2001. Competing for Attention in Knowledge Markets: Electronic Document Dissemination in a Management Consulting Company. Administrative Science Quarterly 46(1), 1-28.

Hargadon A., Sutton R.I., 1997. Technology brokering and innovation in a product development firm. Administrative Science Quarterly 42, 716-749.

Heninger, W. G., Dennis, A. R., McNamara Himer, K., 2006. Individual cognition and dual-task interference in group support systems. Information Systems Research 17 (4), 415-424.

Henttonen, K., 2010. Exploring social network on the team level-A review of the empirical literature. Journal of Engineering and Technology Management 27, 74-109.

Hoegl, M., Proserpio, L., 2004. Team member proximity and teamwork in innovative projects. Research Policy 33, 1153-1165.

Hoenig J. M., Heisey, D. M., 2001. The Abuse of Power: The Pervasive Fallacy of Power Calculations for Data Analysis. The American Statistician 55 (1), 19-24.

Isaacs, E., Walendowski, A., Whittaker, S., Schiano, D. J., Kamm, C., 2000. The Character, function, and styles of Instant Messaging in the workplace. Proceedings of the ACM Conference on Computer Supported Collaborative Work, pp. 1-20.

Janssen, O., 2001. Fairness Perceptions as a Moderator in the Curvilinear Relationships between Job Demands, and Job Performance and Job Satisfaction. Academy of Management Journal 44(5), 1039-1050.

Johnson, N. A., Cooper, R. B., 2009. Power and concession in computer-mediated negotiations: an examination of first offers. MIS Quarterly 33 (1), 147-170.

Kozlowski, S. W., Klein, K. J., 2000. A multilevel approach to theory and research in organizations. Contextual, temporal, and emergent processes. In Klein, K.J. and Kozlowski, S. W. (eds) Multilevel Theory, Research, and Methods in Organizations. Foundations, extensions, and new directions. Jossey-Bass, San Francisco, pp. 349-381. 
LeBreton, J. M., Senter, J. L., 2007. Answers to 20 Questions About Interrater Reliability and Interrater Agreement. Organizational Research Methods 11 (4), 815-852.

Leroy, S., 2009. Why is it so hard to do my work? The challenge of attention residue when switching between work tasks. Organizational Behavior and Human Decision Processes 109 (2), 168181.

Li, H., Gupta, A., Luo, X., Warkentin, M., 2011. Exploring the impact of instant messaging on subjective task complexity and user satisfaction. European Journal of Information Systems 20(2), 139-155.

Manning, S., Massini, S. E., Lewin, A. Y., 2008, The Globalization of Innovation: A Dynamic Perspective on Offshoring. Academy of Management Perspectives 22 (3), 35-54.

Maruping, L., Agarwal, R., 2004. Supporting Team Interactions with Technology: A TaskTechnology Fit Perspective. Journal of Applied Psychology 89(6), 975-990.

Maynard, M.T., Mathieu, J.E., Rapp, T.L., Gilson, L.L., 2012. Something(s) old and something(s) new: Modeling drivers of global virtual team effectiveness. Journal of Organizational Behavior 33, 342-365.

Mathieu, J., Maynard, M.T., Rapp, T., Gilson, L., 2008. Team Effectiveness 1997-2007: A Review of Recent Advancements and a Glimpse Into the Future. Journal of Management 34(3), 410-476.

Mortensen, M., 2014. Constructing the Team: The Antecedents and Effects of Membership Model Divergence. Organization Science 25(3), 909-931.

Nardi, B.A., Whittaker, S., Bradner, E., 2000. Interaction and outeraction: instant messaging in action. Proceedings of the ACM conference on Computer supported cooperative work, pp. 1-9.

O'Leary, M.B., Mortensen, M., Woolley, A.W. 2011. Multiple Team Membership: A Theoretical Model of its Effects on Productivity and Learning for Individuals and Teams. Academy of Management Review 36(3), 461-478.

O’Leary, M.B., Woolley, A.W., Mortensen, M. 2012. Multiteam membership in Relation to Multiteam Systems, In Zaccaro, S.J., Marks, M.A., DeChurch, L.A. (eds.) Multiteam Systems. An Organization Form for Dynamic and Complex Environments, Routledge, New York, NY, pp. 141-172.

Ocasio, W., 1997. Towards an Attention-Based View of the Firm. Strategic Management Journal 18(51), 187-206.

Oh, H., Chung, M.-H., Labianca, G., 2004. Group Social Capital and Group Effectiveness: The Role of Informal Socializing Ties. Academy of Management Journal 47(6), 860-875.

Ou, C.X.J., Zhong, X., Davison, R.M., Liang, Y., 2010. Can instant messaging empower teams at work?, Fourth International Conf. on Research Challenges in Information Science (RCIS), Nice, France, pp. 589-598.

Ou, C. X.J., Davison, R.M. 2011. Interactive or interruptive? Instant messaging at work. Decision Support Systems 52, 61-72.

Pazos, P., Chung, J. M., Micari, M., 2013. Instant Messaging as task-support tool in Information Technology organizations. Journal of Business Communication 50 (1), 68-86.

Perlow, L.A., 1999. The Time Famine: Toward a Sociology of Work Time. Administrative Science Quarterly 44(1), 57-81.

Quan-Haase, A., Cothrel, J., Wellman, B., 2005. Instant Messaging for Collaboration: A Case Study of a High-Tech Firm. Journal of Computer-Mediated Communication doi: 10.1111/j.10836101.2005.tb00276.x 
Radicati S., 2012. Corporate IT and Business User Survey, 2012-2013. The Radicati Group. Retrieved May $22^{\text {nd }} 2013$, http://www.radicati.com/wp/wp-content/uploads/2012/08/Corporate-IT-andBusiness-User-Survey-2012-2013-Executive-Summary2.pdf

Reagans, R., McEvily, B., 2003. Network Structure and Knowledge Transfer: The Effects of Cohesion and Range. Administrative Science Quarterly 48(2), 240-267.

Reagans, R., Zuckerman, E.W., 2001. Networks, Diversity, and Productivity: The Social Capital of Corporate R\&D Teams. Organization Science 12(4), 502-517.

Rennecker, J., Godwin, L., 2005. Delays and interruptions: a self-perpetuating paradox of communication technology use. Information and Organization 15, 247-266.

Rodan, S., Galunic, C., 2004. More than network structure: how knowledge heterogeneity influences managerial performance and innovativeness, Strategic Management Journal, 25(6), 541-562.

Rubinstein, J. S., Meyer, D. E., Evans, J. E., 2001. Executive control of cognitive processes in task switching. Journal of Experimental Psychology 27, 763-797.

Schultz, C., Schreyoegg, J, von Reitzenstein, C., 2013. The moderating role of internal and external resources on the performance effect of multitasking: Evidence from the R\&D performance of surgeons. Research Policy, 42, 1356-1365.

Sparrowe, R.T., Liden, R.C., Wayne, S.J., Kraimer, M.L., 2001. Social Networks and the Performance of Individuals and Groups. Academy of Management Journal 44(2), 316-325.

Speier C., Vessey I., Valacich J. S., 2003. The effects of interruptions, task complexity, and information presentation on computer-supported decision-making performance, Decision Sciences 34 (4), 771-797

Suh, K.S., 1999. Impact of communication medium on task performance and satisfaction: an examination of media-richness theory. Information \& Management 35(5), 295-312.

Taylor, H., Fieldman, G., Altman, Y., 2008. E-mail at work: A cause for concern? The implications of the new communication technologies for health, wellbeing and productivity at work. Journal of Organisational Transformation \& Social Change 5 (2), 159-173.

Tennenbaum, S.I., Mathieu, J.E., Salas, E., Cohen, D., 2012. Teams Are Changing: Are Research and Practice Evolving Fast Enough? Industrial and Organizational Psychology 5, 2-24.

Treem, J. W., Leonardi, P., 2012. Social media use in organizations. Exploring the affordances of visibility, editability, persistence, and association. Communication Yearbook 36, 143-189.

Tucker, A.L., Nembhard, I.M., Edmondson, A.C., 2007. Implementing New Practices: An Empirical Study of Organizational Learning in Hospital Intensive Care Units. Management Science 53(6), 894-907.

Tudor, B., Pettely, C., 2010. Gartner Says Social-Networking Services to Replace E-Mail as the Primary Vehicle for Interpersonal Communications for 20 Percent of Business Users by 2014. Retrieved December 13, 2011, http://blogs.gartner.com/symposium-live/2010/11/11/gartnersays-social-networking-services-to-replace-e-mail-as-the-primary-vehicle-for-interpersonalcommunications-for-20-percent-of-business-users-by-2014/

Van der Vegt, G.S., Bunderson, S., Kuipers, B., 2010. Why turnover matters in self-managing teams: learning, social integration, and task flexibility. Journal of Management 36, 1168-1191.

Wageman, R., Hackman, J.R., Lehman, E., 2005. Team Diagnostic Survey: Development of an Instrument. The Journal of Applied Behavioral Science 41, 373-398.

Wageman, R., Gardner, H., Mortensen, M., 2012a. Teams have changed: Catching up to the future. Industrial and Organizational Psychology 5(1), 48-52.

Wageman, R., Gardner, H., Mortensen, M., 2012b. The changing ecology of teams: New directions for teams research. Journal of Organizational Behavior 33, 301-315. 
Wasserman, S., Faust, K., 1994. Social network analysis: Methods and applications. Cambridge University Press, Cambridge, MA.

Wong, S.-S., 2008. Task knowledge overlap and knowledge variety: the role of advice network structures and impact on group effectiveness. Journal of Organizational Behavior 29(5), 591614.

Zaccaro, S.J., Marks, M.A., DeChurch, L.A., 2012. Multiteam Systems. An Organization Form for Dynamic and Complex Environments, Routledge, New York, NY.

Zellmer-Bruhn, M.E., 2003. Interruptive Events and Team Knowledge Acquisition. Management Science 49(4), 514-528. 
FIGURE 1

Hypothesized relationships

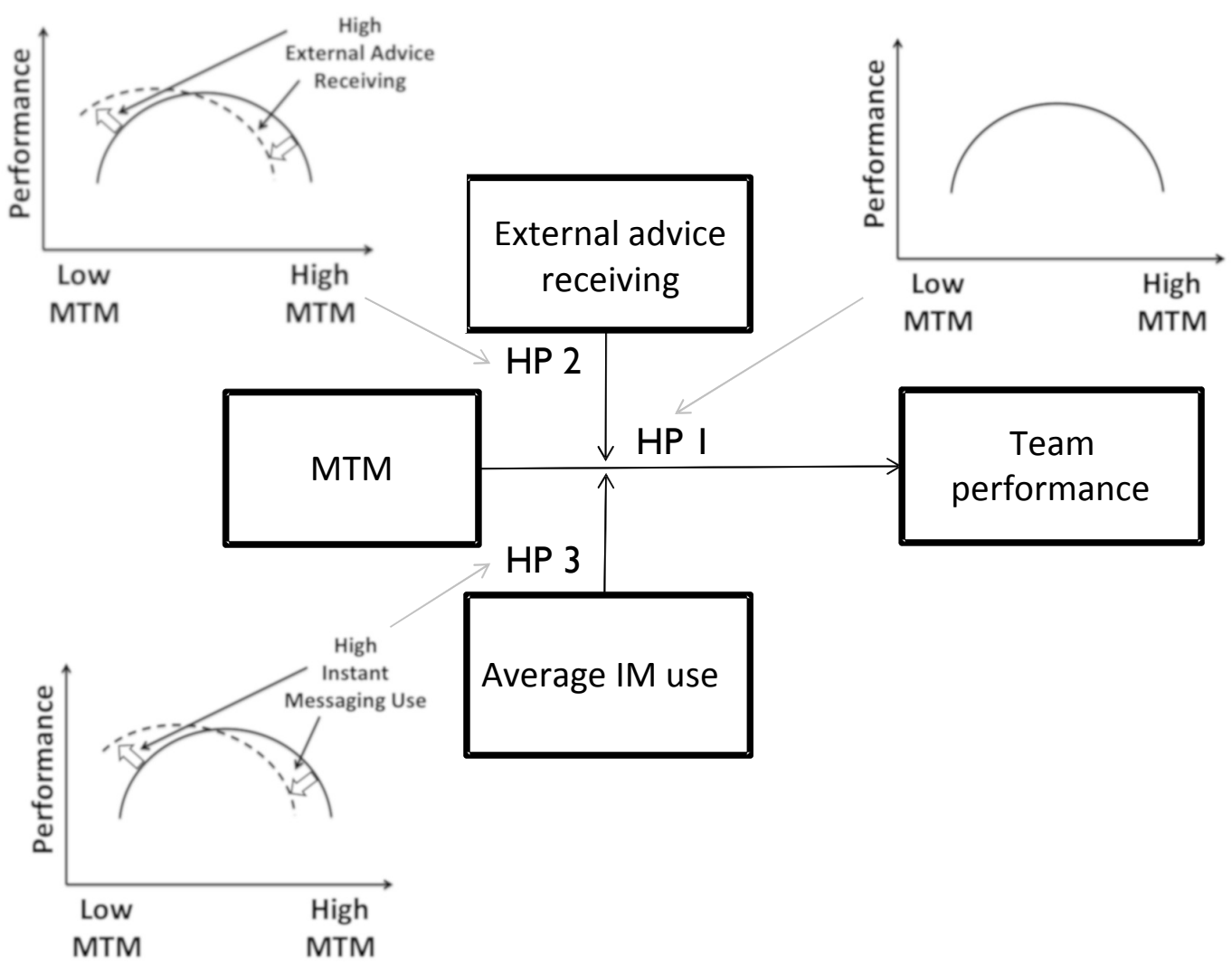


FIGURE 2

Moderating Effect of External Advice Receiving on the Inverted U-Shaped Relationship between Multiple Team Membership and Team Performance

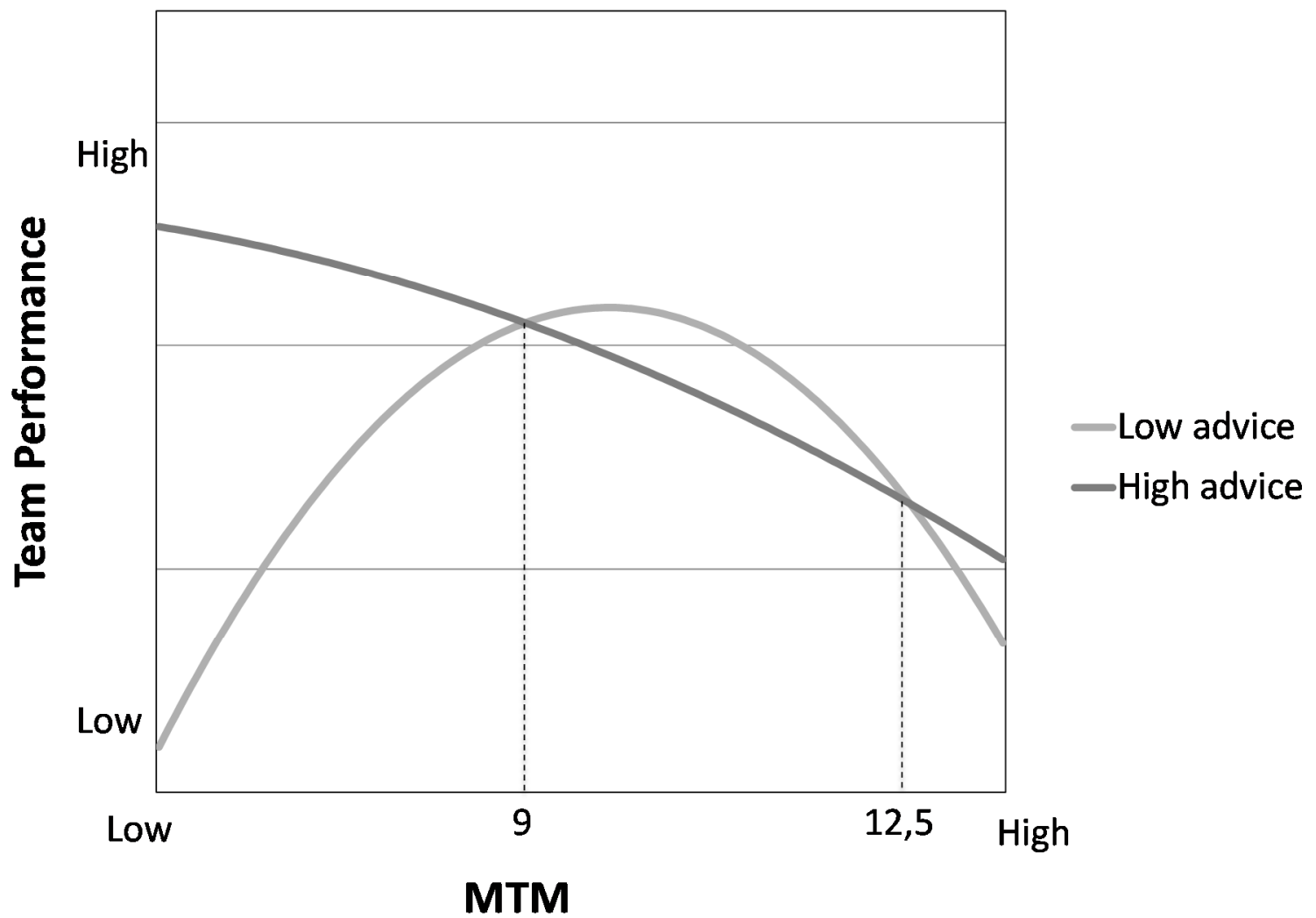




\section{FIGURE 3}

Moderating Effect of Average Use of Instant Messaging on the Inverted U-Shaped Relationship between Multiple Team Membership and Team Performance

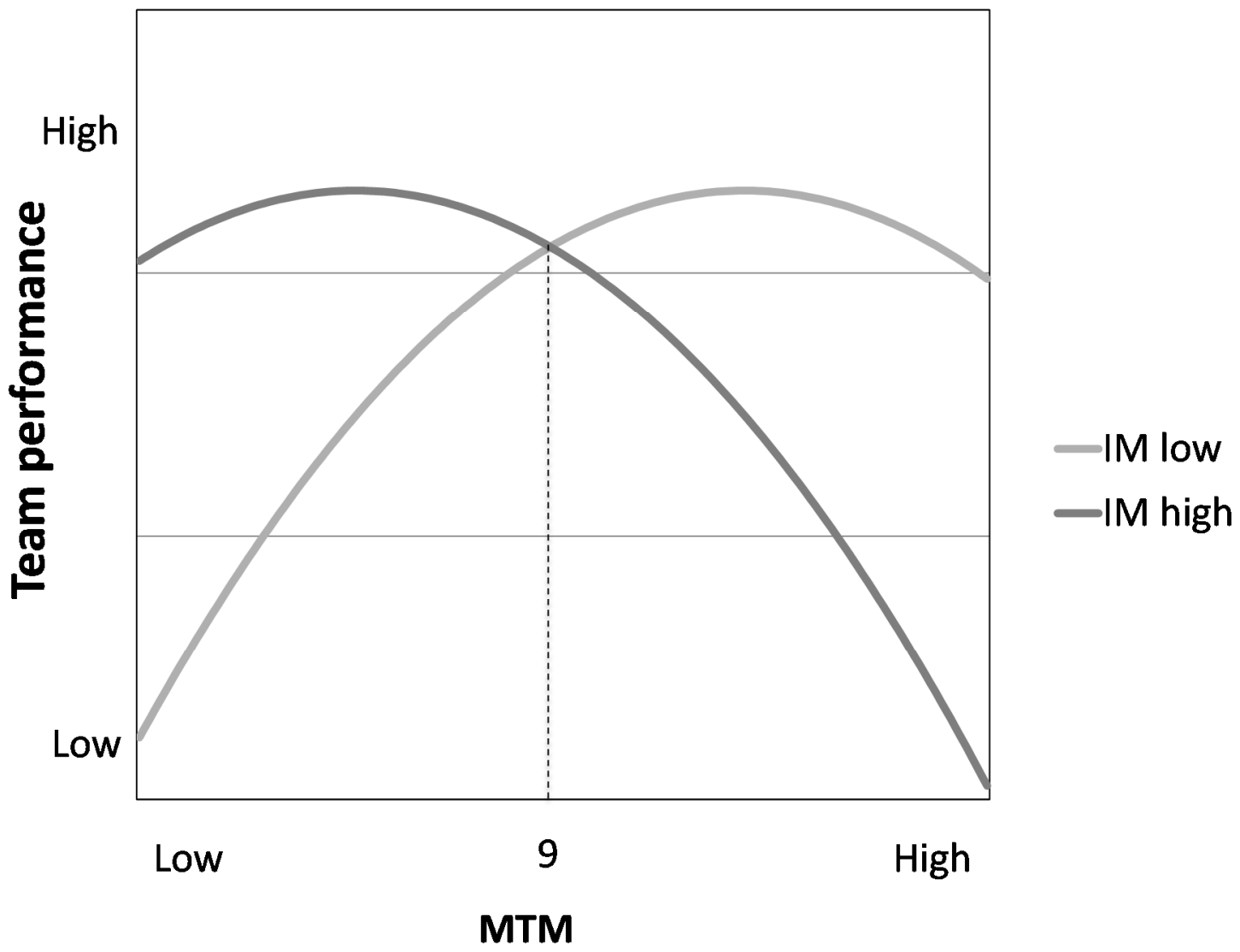




\section{TABLE 1}

Univariate Statistics and Pearson Correlations among Study Variables $(\mathrm{N}=40)$

\begin{tabular}{|c|c|c|c|c|c|c|c|c|c|c|c|c|c|c|}
\hline Variables & Mean & s.d. & Min & Max & 1 & 2 & 3 & 4 & 5 & 6 & 7 & 8 & 9 & 10 \\
\hline \multicolumn{15}{|l|}{ Control } \\
\hline 1. Team size & 6.38 & 5.77 & 2 & 27 & 1 & & & & & & & & & \\
\hline 3. Project Complexity & 1.98 & .66 & 1 & 3 & $0.32^{*}$ & 0.18 & 1 & & & & & & & \\
\hline 4. Average use of email & 3.59 & .42 & 2.00 & 4.00 & -0.07 & $-0.49^{* *}$ & $-0.34^{*}$ & 1 & & & & & & \\
\hline 5. Num. of knowledge areas & 2.35 & 1.08 & 1 & 4 & $0.75^{* * *}$ & 0.02 & 0.19 & -0.05 & 1 & & & & & \\
\hline 7. Localization & .35 & .48 & 0 & 1 & 0.12 & $-0.43^{* *}$ & $0.27^{*}$ & $0.35^{*}$ & -0.04 & 0.26 & 1 & & & \\
\hline \multicolumn{15}{|l|}{ Predictor } \\
\hline 8. Multiple Team Membership (MTM) & 8.92 & 2.16 & 5.00 & 13.50 & -0.13 & $0.55^{* *}$ & 0.10 & $-0.41^{* *}$ & -0.11 & -0.17 & $-0.44^{* *}$ & 1 & & \\
\hline 9. External advice receiving & .12 & .05 & .04 & .27 & 0.08 & -0.13 & 0.09 & -0.09 & 0.11 & -0.06 & -0.05 & 0.28 & 1 & \\
\hline 10.Average use of IM & 2.11 & .72 & 1.00 & 4.00 & -0.10 & $-0.42^{* *}$ & 0.15 & $0.49^{* *}$ & 0.02 & -0.03 & $0.67^{* * *}$ & $-0.45^{* *}$ & 0.11 & 1 \\
\hline \multicolumn{15}{|l|}{ Dependent } \\
\hline
\end{tabular}


TABLE 2

Results of Hierarchical Regression Analysis ${ }^{\mathrm{a}}$

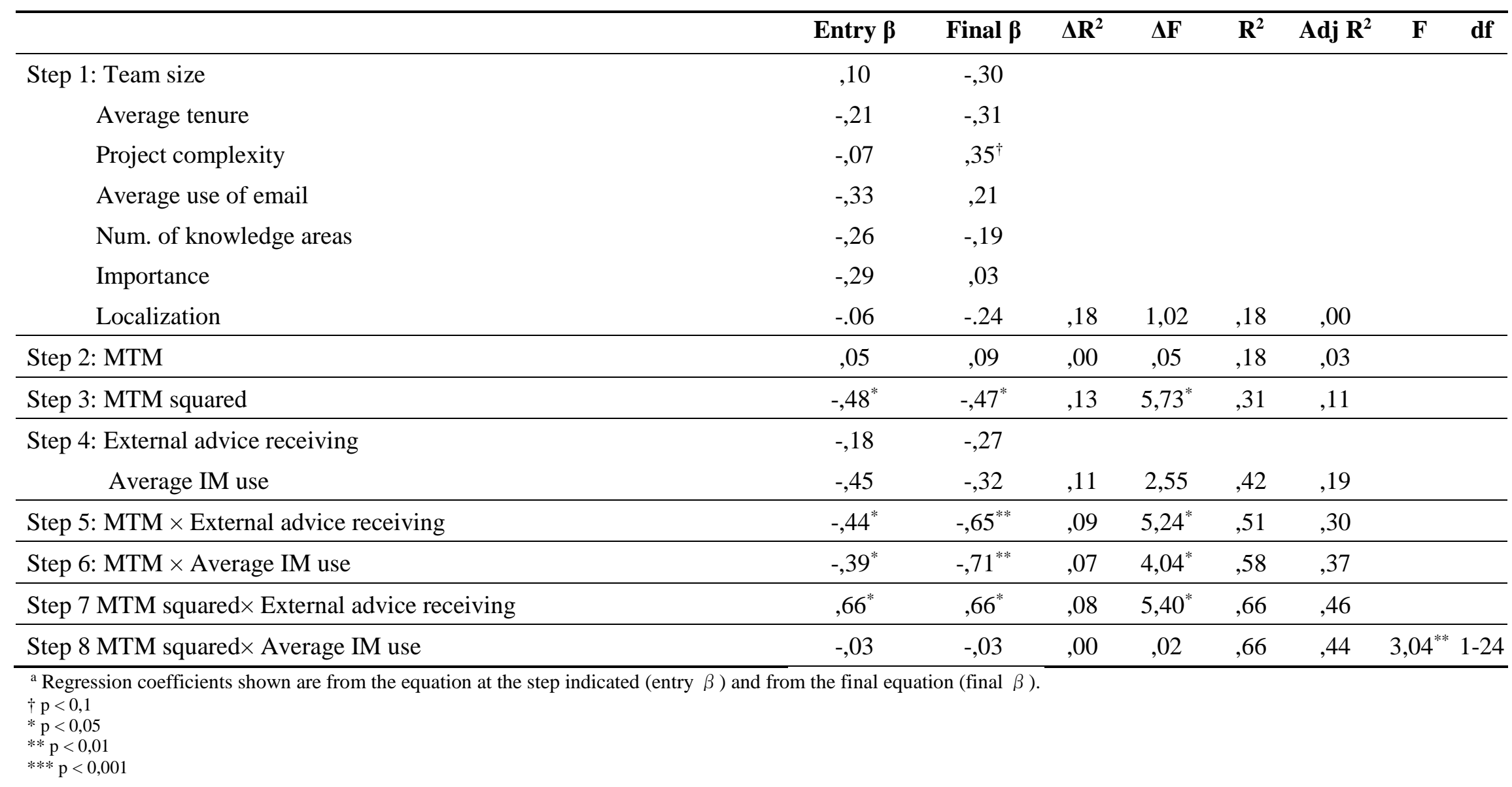

